\title{
DiREITO INTERNaCIONAL PRIVAdo
}

\author{
Da naturalisação e seus effeitos na orbita do \\ direito civil
}

I A naturalisação, segundo Folleville, é um acto do poder publico (em certos casos um beneficio da lei), em virtude do qual um extrangeiro perde a nacionalidade de origem, e adquire a qualidade de cidadão de um outro Estado, em que é admittido a gozar d'ahi por deante de todos os direitos civis concedidos àos naturaes do paiz ( $\mathrm{r}$ ). Não é exacta a definição, porquanto em certos casos o naturalisado, além dos direitos civis, tamberm póde exercer os direitos politicos consagrados pelas leis do Estado que o recebe.

Weiss define: a naturalisação é un acto soberano e discrecionario do poder publico, em consequencia do qual uma pessôa adquire a qualidade de nacional ou de cidadão em um Estado a que não se achava ligada por nenhum vinculo legal anterior (2). A qualidade de nacional, com todos os direitos que lhe são inherentes, só excepcionalmente é conferida pela grande

(I) Traité Théorique et Pratique da la Naturalisation, n. 2, Paris, 1880.

(2) Droit International Privé, tomo I.', pag. 281, Paris, 1892. 
naturalisaçâo. A regra consiste em adquirir o naturalisado a capacidade de exercer os direitos civis da nova patria, com alguns direitos politicos.

No conceito do jurisconsulto patrio, o conselheiro Ribas, a naturalisação é o acto pelo qual uma nação adopta como seu um membro de outra, declarando este preferil-a á sua anterjor nacionalidade (3). Como bem notou o visconde de Ouro Preto, esta definição contém uma condição essencial da naturalisação, a declaração de preferencia da nacionalidade (4). Quer se tracte da naturalisação individual, quer da collectiva, são necessarias sempre duas acções conjunctas e simultaneas, a do naturalisando e a do Estado que o recebe em seu gremio. Por outro lado, porém, a definição de Ribas não nos dá idéa precisa dos direitos adquiridos pelo naturalisado.

Em monographia escripta sobre esta materia, Gorrini resume a sua doutrina, dizendo que a naturalisação é o acto do poder executivo, ou legislativo, por força do qual um individuo ou um conjuncto de individuos, extranhos a um Estado, passam a gosar de todos, ou de parte dos direitos conferidos unicamente aos cidadãos (5). Gorrini accentúa bem que a naturalisação ora confere todos os direitos proprios dos cidadãos do novo Estado, ora sómente parte. Mas, omitte a condição essencial da acquiescencia do naturalisando, e apresenta-nos como unico effeito da naturalisação o goso de todos, ou de parte dos direitos peculiares aos cidadãos, quando é indubitavel que a naturalisação tambem impõe obrigações, equiparando ou quasi equiparando a posição juridica do naturalisado á do cidadão nato.

(3) Direito Administrativo Brasileiro, pag. 269, Rio de Janeiro, 1866.

(4) Direito, vol. 30, pag, $32 \mathrm{I}$.

(5) La Concessione della Cittadinanza, pag. I 2, Voghera, 1890. 
Aproveitando o que ha de verdadeiro em cada uma das definiç̃os transcriptas, parece-nos que bem podemos dizer que a naturalisação é o acto do poder publico, legislativo ou executivo, em virtude do qual uma pessôa, ou um conjuncto de pessôas, mediante sua livre acquiescencia, adquirem a qualidade de cidadãos de outro Estado, e passam a gosar de todos ou de parte dos direitos peculiares aos naturaes do paiz.

II Em Roma já havia a concessão do direito de cidade, individual e collectiva. A donatio civitatis e a erroris causae probatio são, por assim dizer, os germens do instituto da naturalisação. Mas, o direito de cidade em Roma era um favor que a urbs fazia, ou uma medida dictada por conveniencias politicas, muitas vezes para evitar insurreições e guerras sociaes. A naturalisação, com o caracter juridico que hoje tem, é instituto exclusivamente moderno (6).

III A naturalisação se divide em ordinaria, ou pequena naturalisação, e extraordinaria, ou grande naturalisação. Denomina-se ordinaria, ou pequena, a naturalisação em virtude da qual o extrangeiro adquire a nacionalidade, mas não é equiparado aos cidadãos natos, por não ter os mesmos direitos politicos que estes, nem consequentemente a mesma capacidade para exercer todas as funcções publicas. Extraordinaria, ou grande naturalisação é a que confere ao naturalisado, alêm de todos os direitos de ordem civil, todos os direitos politicos de que gosam os naturaes do paiz. Exemplo da naturalisação extraordinaria nos offerece a Colombia na America Hespanhola. Em nosso paiz o que ha, é a naturalisação ordinaria, ou pequena naturalisação; porquanto, posto que apto em geral para o exercicio dos direitos politicos conferidos aos cidadãos

(6) GorrinI, ob. cit., cap. $.^{\circ} .^{\circ}$, WeIss, ob. cit., pags. 284 e segs. 
natos, como os cargos de ministro. e secretario de Estado, deputado, senador, etc., o naturalisado não póde ser presidente nem vice-presidente da Republica, sendo esta a unica excepção ou restricção imposta aos cidadãos naturalisados.

A naturalisação no Brasil, pois, não dá azo ás controversias que se suscitam em outros paizes, como, por exemplo, a Italia, onde muito se tem discutido a questão de saber se o naturalisado póde ser jurado (7). Entre nós a naturalisação abre accesso a todos os cargos e funcções publicas, com a unica limitação apontada.

A naturalisação tambem se divide em individual e collectiva. Collectiva - a que recáe sobre um povo ou parte delle em consequencia da annexação. Individual - a que só aproveita a uma determinada pessôa (8). Tanto a collectiva como a individual são voluntarias; visto como, no caso de se annexar parte de um Estado a outro (e é o que se dá geralmente), os originarios e os habitantes da região annexada, em regra, têm o diveito de opção (9). A naturalisação só é forçada, por não ser possivel o direito de opção, quando um Estado absorve completamente outro (IO).

IV No Brasil, ao congresso federal foi conferida competencia exclusiva para legislar sobre naturalisação (Const. Federal, art. 34, n. 24), o que é um corollario logico do regimen constitucional adoptado. Os presidentes e governadores de Estados só poderão conceder cartas de naturalisação, se essa incumbencia lhes fôr confiada pelo governo federal, de accordo com o disposto no art. $7 .^{\circ}, \S 3 .^{\circ}$, da Const. Federal.

(7) GORRINI, op. cit.; cap. 2.9

(8) Direito, vol. cit., pag. 322.

(9) Folleville, obra citada, ns. 263 e segs.

(IO) FolLeVILLE, n. 267. 
$\mathrm{O}$ aviso de $\mathrm{I} 4$ de janeiro de $\mathrm{I} 893$, expedido pelo ministerio da justiça e negocios interiores, contém a enumeração de todas as nossas leis, decretos e avisos, acerca da naturalisação, no regimem imperial e no vigente (I I). Além dos actos mencionados no aviso, temos a recente lei n. 904, de I 2 de Novembro de I 902, que exige, para a concessão do titulo de naturalisação, prova de: I) identidadade de pessôa; II) maioridade legal; III) residencia no Brasil por dois annos, no minimo; IV) bom procedimento moral e civil, provado por documento official. O naturalisado só póde ser eleito senador depois de seis annos de residencia no paiz, e deputado depois de quatro. Não é permittida a naturalisação dos extrangeiros que estiverem pronunciados, ou condemnados, por algum dos crimes referidos no art. I 3 da lei; nem a naturalisação subtráe o naturalisado ás obrigações por elle contraidas no paiz de origem antes de sua desnacionalisação.

$\mathrm{V}$ Posto que seja nosso intento tractar exclusivamente das consequencias da naturalisação no que concerne ao direito civil, que é onde se deparam ao jurista maiores difficuldades, escreveremos antes duas palavras ácerca dos effeitos da naturalisação no direito penal e no direito commercial.

A lei penal é applicavel a todos os individuos, sem distincção de nacionalidade, que perpetrarem crimes em territorio brasileiro (art. 4..$^{\circ}$ do Codigo Penal). E' tambem applicavel a lei penal ao nacional, ou extrangeiro, que regressar ao Brasil, espontaneamente ou por extradição, tendo commettido fóra do paiz os crimes constantes do art. $5 .^{\circ}$ do Cod. Penal.

Tractando-se, pois, de delictos (no sentido amplo do termo) commettidos no territorio brasileiro, e que

(I I) Vide Gazeta Juridica, de S. Paulo, vol. I., pag. 293. 
no Brasil tenham de ser julgados, nenhuma distincção ha que fazer entre brasileiros natos, naturalisados $\mathrm{e}$ extrangeiros.

Se um extrangeiro pratica em territorio brasileiro um dos crimes cujos auctores estão sujeitos á extradição e depois se ausenta, ou fóra do paiz algum dos delictos referidos no art. $5 .^{\circ}$ do Cod. Penal, tem applicação o disposto neste artigo, e o extrangeiro delinquente está sujeito ao julgamento pelas justiças brasileiras, depois de regularmente extraditado.

$\mathrm{Ha}$, entretanto, uma regra de direito internacional privado, em virtude da qual o Estado a que é pedida a extradição, tem o direito de a negar, desde que o criminoso seja cidadão do Estado requerido. Posto que combatida por Fiore com excellentes e brilhantes argumentos, a regra juridica mencionada é ensinada pela grande maioria dos publicistas, e consagrada pela grande maioria dos tractados internacionaes. "Aux yeux du plus grand nombre des jurisconsultes les plus autorisés, et aux termes de la plupart des Codes, il est admis comme une règle certaine que le national de l'E'tat requis ne saurait, en aucun cas, être livré. Mais, cette doctrine est combattue par une minorité qui a bien sa valezır» (I 2). Se, porém, o criminoso é um cidadão naturalisado, e o crime foi perpetrado antes da naturalisação, tem cabimento a extradição? A hypothese não é destituida de interesse pratico, e já se tem realisado no Brasil. Um italiano, um francez ou um allemão, por exemplo, obtem a naturalisação em nosso paiz, e mais tarde, por se verificar que praticou um crime antes de se naturalisar, é requisitada a sua extradição pelo governo do seu paiz de origem. O criminoso já é cidadão brasileiro naturalisado. Deve ser concedida a

(12) FIORE, Traité de Droit Pénal Internacional et de l'Extradition, trad. de C. Antorne, Paris, I880, vol. 2.', n. 344. 
extradição? A bôa, a verdadeira doutrina é que sim. A naturalisação não tem effeito retroactivo, como d'aqui a pouco veremos proclamado por todos os publicistas e jurisconsultos auctorisados. "Cette question a été écartée dans certains traités par l'insertion de la clause expresse, que l'exception en faveur des nationaux ne doit pas s'étendre aux individus qui ont obtenu la naturalisation après la perpétration du délit. Il en est ainsi dans les conventions conclues par le royaume d'Italie avec la grande Bretagne (article 4), avec la Grèce (article 6), et avec le Brésil (artucle 2). En l'absence de toute clause à ce sujet, il nous semble que cette stipulation doit néanmoins être présumée sous entendue dans les traités. Si, en effet, on peut justifier l'application de la loi de l' E'tat pour la répression des délits commis par le national en tervitoire etranger, on ne saurait certainement justifier l'application de la loi de l'E'tat pour reprimer un delit commis par un individu avant qu'il n'ait acquis la nationalite de cet E'tat. Autrement on donnerait à cette loi un effet retroatif» (I3). Lição identica é a de Weiss, que nos affirma estar a jurisprudencia internacional de accordo com a sua doutrina, que resume do seguinte modo: a questão de nacionalidade nestes casos deve ser apreciada, tendo-se em attenção o momento em que o delicto é praticado, e não o tempo em que o réo é preso, ou processado (I4).

A regra de direito internacional, em summa, nesta materia é que o extrangeiro que, depois de ter commettido em seu paiz de origem um crime dos em que a extradição é permittida, se naturalisa em outro Estado, deve ser extraditado, porquanto a naturalisação não tem effeito retroactivo, não se extende ao passado.

(I3) FIORE, op. cit. n. 375 .

(14) Traité Théorique et Pratique de Droit International Privé, Paris, 1892 , tomo $1 .^{\circ}$, pags. 35 I e $35^{2}$, 
Esta regra tem sido consagrada em tractados feitos pelo Brazil com diversas potencias européas, como na convenção com a Italia, citada por Fiore, de I 2 de novembro de 1872 , e no tractado de extracdição com a Inglaterra, de I 3 de novembro de I 872 , promulgado entre nós pelo dec. n. 5.385, de r..$^{\circ}$ de setembro de I873, apontado por Weiss como um dos mais adeantados neste assumpto.

Quando nas convenções e tractados não é incluida expressamente, a citada regra se presume hoje tacitamente acceita, segundo se vê em Fiore (n. 375).

Entretanto, em diversos tractados está expressamente estipulado que nenhum subdito de uma nação será entregue a outra, ou extraditado, para ser julgado pelas justiças do logar do crime. Tal é a disposição contida no art. $2 .^{\circ}$ do tractado de extradição celebrado entre - Brasil e a Allemanha em 17 de setembro de 1877 , e promulgado entre nós pelo dec. n. 6.846, de 25 de junho de 1878 . Em tal caso, a jurisprudencia brasileira tem entendido que o naturalisado no paiz, depois de ter commettido um delicto na sua patria de origem, deve ser precessado e julgado pela justiça estadoal brasileira, de accordo com o disposto na lei $n$. 2.6I5, de 4 de agosto de I875, no decreto n. 6.934, de 8 de junho de i 878 , e com o art. $50^{\circ}$ do Codigo Penal. Nesse sentido temos o juridico accordam do Tribunal de Justiça do Estado de S. Paulo, de 6 de dezembro de I 892, no processo em que era réo Bruno Klaussener von Hof, allemão naturalisado brasileiro ( I 5).

VI Segundo preceitúa o art. 30 do Cod. Commercial, todos os actos de commercio praticados por extrangeiros residentes no Brasil serão regulados e decididos pelas disposições do mesmo codigo.

(15) Gazeta Juridica, de S. Paulo, vol. 1.․ pag. I83. 
Se nesta materia nenhuma distincção ha entre brasileiros e extrangeiros, seria absolutamente ocioso indagar as consequencias da naturalisação do extrangeiro commerciante.

E' no art. $3 .^{\circ}, \S$ i. ${ }^{\circ}$, do regul. n. 737 , de 25 de novembro de 1850 , que se nos depara alguma cousa da esphera do nosso estudo. Ahi se estatue que as leis e usos commerciaes dos paizes extrangeiros regulam as questões sobre o estado e edade dos extrangeiros residentes no paiz, quanto á capacidade para contractar, não sendo os mesmos extrangeiros commerciantes matriculados.

Em primeiro logar, a distincção entre commerciantes extrangeiros matriculados e não matriculados, para o fim de sujeitar os primeiros ás leis brazileiras nas questões relativas ao estado e edade (na linguagem do regul.), e os segundos ás dos respectivos paizes, é um absurdo tão repugnante aos rudimentos do direito, que, com razão disse $\mathrm{T}$. de Freitas, deve reputar-se não escripta ( I6). A materia é do dominio do direito internacional privado; a capacidade dos extrangeiros é regulada pelas leis dos seus respectivos paizes, pouco importando que o negociante seja, ou não, matriculado. A matricula absolutamente não produz, não póde produzir (porque o direito internacional o veda) o effeito que só á naturalisação é dado, de alterar as normas juridicas reguladoras do estado e capacidade do extrangeiro.

As leis extrangeiras regulam as questões sobre o estado e edade dos extrangeiros commerciantes no Brazil. Verificada a naturalisação de um commerciante extrangeiro, quaes as consequencias do facto sobre a capacidade do naturalisado?

(16) Additamentos, vol. I..$^{\circ}$ pag. 298. 
A resposta a esta pergunta tem seu logar na segunda parte do nosso estudo, effeitos da naturalisação na orbita do direito civil.

$$
*^{*} *
$$

VII Duas questões preliminares se apresentam a quem investiga os effeitos da naturalisação na orbita do direito civil. A naturalisação do marido importa a da mulher? Naturalisado o pae de familia, estão ipso facto naturalisados os filhos menores?

E' preciso não confundir a primeira questão com a resolvida pela nossa lei n. r.o96, de ıo de setembro de 1860 , lei que ainda está em vigor, como declarou o aviso, já citado, de 14 de janeiro de I893, do ministerio da justiça e negocios interiores, porquanto não foi revogada, nem está em antinomia com qualquer dos artigos da Const. Federal, neste ponto conforme á Const. de 25 de março de 1824. A lei de I 860 declara que a extrangeira que casar com brazileiro, seguirá a condição do marido, assim como a brazileira que casar com extrangeiro, seguirá a condição deste.

Em tal caso, é a naturalisação consequencia do casamento, acto querido, praticado voluntariamente pela mulher, e consequentemente não ha nacionalidade imposta, possibilidade de surpresas, ou de abusos e fraudes que por ventura pratique o marido em prejuizo da mulher. Admittida a naturalisação da mulher como effeito necessario da do marido, sem que da parte daquella haja qualquer declaração de vontade, o resultado será poder o marido a seu talante, á feição de seus interesses, mudar a nacionalidade da mulher, como bem demonstra Laurent (i 7).

(17) Le Droit Civil International, vol. $34^{\circ}$, ns. 162 e 163 . 
Se assim claudica a doutrina pelo lado das consequencias gravissimas que della decorrem, não menos inacceitavel é, quando se attenta no principio em que assenta. A acquisição de nova nacionalidade é um contracto pessoal ( I 8). Já desde o direito romano a inudança de nacionalidade era reputada acto pessoal (I9). A doutrina juridica, pois, é a dos que sustentam não importar a naturalisação do marido a da mulher, excepto quando esta egualmente manifesta a vontade de mudar de patria (20).

Entretanto, não é essa a theoria que tem sido acceita entre nós. Baseando-se na lei n. 8o8, de 23 de junho de 1855 , que nesta parte se acha em geral re- produzida na recente lei de $\mathrm{I} 2$ de novembro de 1902, Pimenta Bueno entende que em nosso paiz a naturalisação do marido acarreta sempre a da mulher, doutrina que considera sufficientemente fundamentada pela necessidade de manter a unidade dos direitos da familia (2 I). A razão de ser da opinião do publicista e jurisconsulto patrio é vantajosamente combatida por Fiore e Folleville, nas passagens indicadas.

VIII Pelos mesmos fundamentos a naturalisação do pae não importa a dos filhos menores (22)

Ainda nesta parte a opinião que tem prevalecido em nosso paiz é a de que, pela necessidade de manter a unidade juridica na familia, os filhos menores que vivem em companhia do pae, mudam de nacionalidade pela naturalisação do pae (23).

$$
* *
$$

(18) FIORE, Droit International Privé, ns. 66 a 68.

(I9) GaIo, Institutas, liv. $\mathbf{1}^{\circ}, \S 93$ e segs.

(20) FolleVILLE, ns. 553 a 555.

(21) Direito Internacional Privado, n. 57.

(22) Fiore, n. 68, Tolleville, ns. 544 a $55 \mathrm{I}$.

(23) Pimenta Bueno, ibidem. 
IX Quaes os etfeitos da naturalisação no que concerne aos direitos civis do naturalisado?

Um principio superior domina a materia, acceito por todos os publicistas, sem a menor discrepancia: a naturalisação não tem effeito retroactivo. Eis as palavras de Calvo: "La naturalisation n'a point d'effet rétroactif. La condition de l'étranger naturalisé se trouve réglée par la loi du pays d'adoption dès le moment de la naturalisation, mais seulement à partir de ce moment-là; sa condition antérieure reste soumise à la loi d'origine: d'ou il suit qu'en règle générale toutes les questions de capacité se référant à des faits accomplis avant la naturalisation devront être appréciées d'après la loi d'origine du naturalisé. La naturalisation n'altère en rien les droits acquis avant son accomplissement, ni même les conséquences légales qui découlent de ces droits antérieurs. Mais, de même que le changement de nationalite ne porte point atteinte aus droits acquis en faveur du naturalisé, il ne peut non plus, en porter aus droits acquis contre lui» (Manuel de Droit International, Public et Privé, § I 89). Do mesmo sentir Fiore (24)e Weiss (25) A lição de Folleville vale a pena reproduzir textualmente: "Qu'il s'agisse d'une naturalisation proprement dite ou par le bienfait de la loi: peu importe. Dans tous les cas, il y a absence complète de retroactivité. C'est d'ailleurs, un principe tellement nécessaire, qu'il n'a pas besoin d'être justifié» (26).

Todos os actos praticados pelo extrangeiro, accrescenta Weiss, todas as obrigações por elle assumidas, antes da naturalisação, devem ser respeitados, e, se não são contrarios á ordem publica internacional, pódem ser invocados perante os tribunaes do paiz adoptado.

(24) Delle Disposisioni Generali, vol. 2. ${ }^{\circ}$ n. 253.

(25) Droit International Privé, vol. 1..$^{\circ}$ pag. 348.

(26) Obra citada, n. 560. 
Nem ao extrangeiro é licito, para se furtar ás consequencias dos seus actos juridicos anteriores, ou do seu anterior estado, invocar-- por exemplo-que, ao tempo em que se obrigou, não tinha attingido a maioridade-segundo a lei da nova patria; basta que nessa épocha tenha sido capaz segundo o direito de seu paiz de origem (27).

Laurent nos explica muito clara e precisamente quaes os effeitos da naturalisação na esphera do direito civil. Sua doutrina está synthetisada nas seguintes palavras: "Le changement de nationalitè n'a pas d'effet quant au passé, en ce qui concerne le statut personnel. Ici la matière des status trouche à celle de la non - rétroactivité» (28). Consequentemente, indagar quaes os effeitos da naturalisação sobre os direitos civis do naturalisado, equivale a averiguar quaes os effeitos da promulgação de uma nova lei na vida civil dos cidadãos de um Estado.

Quando se tracta de relações de direito de tal naturesa, que as leis respectivas não têm effeito retroactivo, tambem a naturalisação não produz effeito retroactivo. Nos casos em que a lei se extende ao passado, tambem a naturalisação produz o mesmo effeito.

Estabelecer essas verdades geraes, por todos acceitas, inconcussas, é facil. Della deduzir regras especiaes-difficillimo. Vamos applicar os principios firmados a algumas das principaes questões que mais frequentemente pódem suscitar-se.

E' manifesto que temos implicitamente partido da doutrina de que o estatuto pessoal depende da nacionalidade, e não do domicilio.

(27) Obra citada, vol. 1., pags. 349 e $35^{\circ}$.

(28) Obra citada, vol. $3 .^{\circ}$, n. 284 . 
Se adoptassemos esta ultima theoria, outra seria a direcção do nosso estudo.

$\mathrm{X}$ A naturalisação modifica o estatuto pessoal do naturalisado, altera-lhe o estado e a capacidade, visto como a capacidade não é direito adquirido. Segundo o art. 320 do Cod. Civil Hespanhol, a maioridade começa aos 23 annos. Supponhamos que um hespanhol, tendo 22 annos de edade, se naturalise no Brasil. Deixará de ser menor, porque aos $2 \sqrt{ }$ annos termina a menoridade em virtude do direito da nova patria. Se, pelo contrario, o naturalisado fôr um turco, e adquirir a nacionalidade brasileira aos i 8 annos, por exemplo, edade em que já é maior no seu paiz, passará a ser menor até aos 2 I annos na patria de eleição (29). A edade em que começa a maioridade, em summa, será determinada pelo direito da nova patria (30).

Se a capacidade não é um direito adquirido, della - entretanto-pódem decorrer direitos irrevogaveis. Assim, os contractos celebrados pelo maior que em virtude da naturalisação se torna menor, são validos, e a naturalisação em nada os modifica (3 I)

Rejeitado o principio do domicilio, e acceito o da nacionalidade, não têm cabimento as distincções feitas por Savigny acerca da maioridade, como demonstra Laurent (32).

XI A mudança de nacionalidade, é ocioso dizel-o, não inflúe no casamento celebrado validamente, de accordo com as leis da primitiva patria.

A mudança de nacionalidade não invalida, nem modifica, os contractos feitos anteriormente, assim como

(29) Na Turquia a menoridade termina aos I5 annos, segundo attesta DEL Vecchio, La famiglia rispetto alla societá civile e al problema sociale.

(30) LAURENT, Obra citada, vol. $3 .^{\circ}$, ns. 288 e 289,

(3I) LAURENT, ibidem.

(32) Ibidem, e n. 287, 
nằo revalida nenhum acto juridico nullo; e, portanto, não póde alterar os effeitos do casamento, contracto sui generis, de que depende a ordem social (33). Está regra presuppõe o casamento celebrado de accordo com os bons costumes, ou, mais precisamente, com as leis reguladoras das condições de conservação da sociedade. Assim por exemplo, naturalisado um extrangeiro polygamo, por ser legal a polygamia no seu paiz de origem, em um Estado que considera um delicto essa forma de união sexual, o casamento polygamico não é admittido, ou reputado valido, no Estado naturalisante (34). Quando porém as condições do casamento, estabelecidas pelas leis do paiz de origem, são diversas das que fixa o direito da nova patria, mas essas condições não interessam á conservação da sociedade (e é isto o que se verifica frequentemente), o casamento é considerado valido no Estado naturalisante. $E$ ' assim que pouco importa que o naturalisado tenha casado antes da edade exigida pelo direito da nova patria, ou sem o consentimento dos ascendentes, quando esse direito o exige.

Essas e outras condições do matrimonio são regidas exclusivamente pelas leis do logar e do tempo em que o contracto se effectúa, o que nada mais é do que a applicação de uma conhecida regra da theoria da retroactividade das lei, theoria que nos fornece os principios e os preceitos applicaveis ás questões do nosso estudo, confórme já vimos (35).

São effeitos do casamento a relativa incapacidade civil da mulher e o poder marital. IJada a naturalisação, por que leis se regulam esses factos? Se a naturalisação comprehende o marido e a mulher, não

(33) LaURent, n. 290.

(34) LAURENT, n. 290.

(35) LAURENT, n. 290. 
ha motivo para controversias: é a lei da nova patria que regula o poder marital e a incapacidade da mulher (36), o estado e a capacidade dos naturalisados. A materia só offerece difficuldades, quando se tem de resolver as questões dentro da theoria dos que, baseados no principio da personalidade da naturalisação, entendem que a naturalisação do marido não se extende á mulher. Laurent e Folleville tractam deste ponto, para nós destituido de interesse pratico; pois, como já vimos, em nosso paiz tem sido admittida a doutrina que, attendendo á necessidade de ser uno o direito da familia, considera a naturalisação da mulher uma consequencia juridicamente necessaria da do marido, doutrina aliás acceita por diversas nações cultas.

XII O regimen de bens da sociedade conjugal é estabelecido por convenção, por um contracto antenupcial, ou, na falta deste, por disposição da lei. Neste. ultimo caso, e segundo a melhor doutrina, o que temos é uma convenção tacita. O legislador presume que os conjuges querem viver sob a regimen da communhão de bens, e os esposos, conhecendo préviamente o preceito legal, acceitam voluntaria e tacitamente esse regimen, quando não fazem uma convenção expressa em contrario.

Adoptado um regimen qualquer dos permittidos pelo direito por occasião de se celebrar o casamento, qual o effeito da naturalisação neste particular?

$\mathrm{Na}$ doutrina dos que ensinam que a naturalisação do marido não importa a da mulher, não ha razão para hesitações: a naturalisação do marido, sem a da mulher, em nada modifica o regimen patrimonial da sociedade conjugal. Se, porém, se admittir que a na-

(36) LaURent, n. 297. 
turalisação do marido produz como effeito a da mulher, ou se ambos os conjuges se naturalisarem conjuncta e livremente, ter-se-á por isso alterado o regimen de bens do casal? Folleville entende que sim, desde que a lei da nova patria disponha diversamente. Pouco importa, accrescenta elle, que a lei do paiz de origem declare irrevogavel o regimen matrimonial; a revogabilidade, ou irrevogabilidade, desse regimen é preceito de ordem publica, e cada paiz estatúe livremente suas regras juridicas de ordem publica. Nem se objecte, ainda é Folleville quem disserta, que o esposo mais fraco póde ser dominado e lesado pelo mais forte; nada obrigava aquelle a mudar de patria. E por aqui se vê que Folleville não admitte que a naturalisação do marido acarrete a da mulher. Cremos que essa doutrina não está de accordo com os principios firmados pelo proprio escriptor, cujas idéas resumimos. Quer a mulher se tenha naturalisado conjunctamente com o marido por acto de sua livre vontade, quer a naturalisação tenha decorrido sómente da do marido, parece-nos que a verdade está com Laurent e com todos aquelles que sustentam não importar a naturalisação modificação de qualquer especie no regimen patrimonial dos conjuges. Nas convenções matrimoniaes, doutrina Laurent, a lei nada impõe ás partes; são estas que fazem a lei sob cujo imperio querem viver. No caso, pois, de modificação nas leis, não ha conflicto entre duas leis da mesma natureza, uma anterior e outra posterior; o que temos b́ de um lado a lei creada pelos proprios contractantes, que estabeleceram um regimen patrimonial irrevogavel, e do outro disposições estatuidas pelo poder publico, e portanto regras de natureza diversa (36).

(36) Laurent, vol. $3 .^{\circ}$, ns. 298 a 300. 
O fundamento principal da nossa opinião é que a materia sobre a qual escrevemos está sujeita, no consenso unanime dos jurisconsultos e dos publicistas, aos principios e ás regras da theoria da retroactividade das leis. E' o que por seu turno ensina Gabba, reproduzindo a lição de Weber, Meyer, Savigny e outros. Todos estão concordes em que «in quei casi nei quali si può applicare la legge nuova ad anteriori contingenze, si possa anche applicarla a contingenze verifisatesi in estero Stato, sulle quali si debba decidere nello Stato, e che non si possa applicare la legge nuova in quei casi nei quali la legge estera dovrebbe essere applicata invece della nazionale» (37). Para termos uma idéa exacta do que é direito adquirido, precisamos estudar o assumpto na theoria da retroactividade e no direito internacional privado: "Il concetto completo del diritto acquisito non $\dot{e}$ soltanto il concetto di un diritto acquistato in un tempo determinato, ma il concetto eziandio di un diritto acquistato in un determinato luogo» (38). Posto que partindo de dois principios diversos, a theoria da retroactividade das leis e o direito internacional privado sobre esses dois principios fundamentaes differentes estabelecem os mesmos principios e as mesmas regras (39).

Ora, na theoria da retroactividade das leis está assentado como "principio generalmente ricevuto dagli scrittori e dai tribunali, e consentaneo alle nostre precedenti dottrine, sia intorno alla retroattività in generale, sia intorno alla retroattività delle legge concernenti le obbligazioue ed $i$ contratti, che il contratto matrimoniale, $e$, piu in generale parlando, $i$ rapporti patrimoniale dei coningi, debbansi in ogni tempo $e$ in tutti $i$ loro effetti

(37) Teoria della Retroattività delle Leg.gi, vol. I ${ }^{\circ}$, pag. 135, Turim, 1884.

(38) GabBa, vol. cit., pag. 136.

(39) GabBa, pag. 137 . 
regolare secondo la legge sotto il cui impero il matrimonio è stato conchiuso, e propriamente non soltanto rispetto alle espresse patuizioni, di coniugi, ma altresi rispetto alle loro tacite convenzioni, desunte dalle leggi $o$ dalle consuetudini vigenti, alle quali si deve ritenere che $i$ coniugi col loro silenzio abbiano inteso riportarsi» (40). $\mathrm{E}$ em apoio desta doutrina cita Gabba uma torrente infinita de jurisconsultos.

Que são as leis vigentes ao tempo da celebração do matrimonio as que regern as convenções matrimoniaes durante todo o decurso da sociedade conjugal, era principio já firmado pelos romanos na Const. unica do Cod., De rei uxoriae actione, e no cap..$^{\circ}$ da $N o-$ vella 22.

Demais, como reconhece o proprio Folleville, esta doutrina que acceitamos, é a unica a offerecer garantias aos direitos e interesses dos conjuges e aos direitos dos terceiros com quem elles contractem.

XIII A lei que permitte, ou prohibe, o divorcio, é de ordem publica, e por isso se applica aos factos passados, isto é, aos casamentos celebrados antes da promulgação da lei. Dada a retroactividade da lei que estatúe ácerca do divorcio, facilmente se comprehendem os effeitos da naturalisação no que toca a este assumpto.

Naturalisa-se no Brazil um extrangeiro cujo paiz de origem permitte o divorcio, e que se casou, portanto, sob o regimen de uma lei que não lhe vedava a dissolução do vinculo matrimonial. Poderá requerer seu divorcio no Brazil? Absolutamente não, pois nesta materia não ha direitus adquiridos, as leis que regulam o estado e a capacidade das pessôas são leis retroactivas, como temos visto.

(40) GABBA, vol. $4 .^{\circ}$, pag. 345 . 
Naturalisa-se no paiz um extrangeiro divorciado, pois que no seu paiz de origem o divorcio é licito. Póde casar-se de novo no Brazil, que não admitte o divorcio? Inquestionavelmente sim.

$\mathrm{O}$ art. $70^{\circ} \S 2 .^{\circ}$, da lei $\mathrm{n}$. $\mathrm{r} 8 \mathrm{I}$, de 24 de janeiro de I 890 , prohibe o casamento ás pessoas ligadas por outro casamento ainda não dissolvido. $O$ casamento de que se tracta foi dissolvido pelo divorcio, e consequentemente desappareceo o impedimento dirimente de que cogita a lei. Nem se objecte que a art. 93 da citada lei só reconhece a dissolução do matrimonio pela morte de um dos conjuges.

A objecção seria disparatada, porquanto o naturalisado, quando se divorciou, estava sujeito a uma lei que consagrava esse meio de dissolução do casamento, e não ao disposto na lei brazileira.

E' deante de exemplos como esse que Laurent, comprehendendo a razão fundamental da não retroa. ctividade da naturalisação, exclama: o homem só póde ter uma patria, e, se a naturalisação retroagisse, teria duas patrias. Realmente, dar-se-ia o absurdo sesquipedal de ficar uma mesma pessôa subordinada ao mesmo tempo ao direito civil de duas nações differentes.

Esposos cujo casamento foi celebrado em um paiz que não permitte o divorcio, se naturalisam em um Estado onde o divorcio é licito. Podem divorciar-se? A resposta á pergunta tal como foi formulada, não é difficil. Dada a naturalição dos dois conjuges, que por isso ficam sujeitos ao direito civil da nova patria em tudo o que diz respeito ao seu estado e capacidade, tem-se opinado geralmente que os naturalisados podem obter o divorcio, abrindo-se uma excepção unica para o caso de naturalisação fraudulenta, isto é, para a hypothese em que os conjuges se naturalisam em um paiz que admitte o divorcio, não com o fim de mu- 
darem de patria, mas sómente para conseguirem o divorcio, para fraudarem a lei da sua nação (4I).

Se um só dos consortes se naturalisa, e a naturalisação não é fraudulenta, ainda se tem entendido que os tribunaes do paiz que permitte o divorcio, verificado algum dos casos de dissolução do vinculo matrimonial, podem decretal-a. Só ha grande divergencia quanto ao poder o conjuge pertencente ao Estado que não reconhece o divorcio contrair segundo casamento. Folleville pensa que sim: mas, os seus argumentos não convencem (42).

XIV A naturalisação do pae e dos filhos menores produz o effeito de subordinar o patrio poder ás normas juridicas da nova patria. Do momento da naturalisação por deante o patrio poder deixa de ser regulado pelo direito do paiz de origem, para ser regulado pelo direito do Estado naturalisante. Acerca deste ponto não póde haver controvercia justificavel.

A difficuldade surge, quando se dá a naturalisação do pae sem a dos filhos menores. Não se supponha que esta hypothese é despida de interesse para nós, por ser doutrina acceita no paiz a de Pimenta Bueno, que reputa a naturalisação dos filhos menores consequencia juridicamente necessaria da do pae. $O$ proprio Pimenta Bueno limita a sua regra: a naturalisação do pae só importa a dos filhos menores que vivem em companhia delle. Consequentemente, sempre que o pae se naturalisa em nosso paiz, não tendo em sua companhia os filhos menores, no proprio conceito de $\mathrm{Pi}$ menta Bueno deve applicar-se a doutrina que se basêa no principio da personalidade da naturalisação. O fundamento da unidade dos direitos na familia não vae ao ponto de justificar a naturalisação dos filhos mẹe-

(41) LAUREN'T, vol. citado, n. 302,

(42) Obra citada n. 623 . 
nores neste caso especial. Temos, portanto, o pae naturalisado, e os filhos menores extrangeiros. Por que direito se regula o patrio poder?

Primeiro que tudo, enunciemos uma verdade ociosa: o pae nas condições figuradas não deixa de ter o poder paternal. O direito que regula esse poder, é o da nação a que pertencem os filhos a elle sujeitos (43). $\mathrm{Na}$ organisação juridica do patrio poder não é mais o interesse do pae, como em Roma, que predomina; é o interesse do filho. Nada, pois, mais logico do que a conclusão que dessa verdade tira o direito internacional privado, sujeitando o patrio poder neste caso ao direito do Estado de que são cidadãos os filhos menores.

XV O extrangeiro não póde ser tutor de um brazileiro (44). Verificada a naturalisação, desapparece a incapacidade.

Sendo o menor extrangeiro, deve dar-se-lhe um tutor de sua nacionalidade (45).

Naturalisado um extrangeiro menor, o que só póde realisar-se em caso de annexação, porquanto o menor não póde naturalisar-se individualmente, é manifesto que se lhe deve nomear um tutor brazileiro.

XVI A naturalisação de um extrangeiro não inhibe os parentes do naturalisado de requererem a interdicção do mesmo, por loucura ou prodigalidade. A interdicção tem por fim conservar o patrimonio do interdicto, e assegurar a transmissão de seus bens a seus herdeiros legitimos. Desde, pois, que se tracte de parentes do naturalisado que lhe tenham direito eventual

(43) Folleville, ns. 627 a 630.

(44) Aviso de 8 de junho de 1837, Lafayetre, Dir. de Familia, § 148, C. Bevilacqua, Dir. da Familia, § 81. Carlos de Carvalho (Nova Consolidação, art. $1.65^{2}$ ), entende que só está excluido o extrangeiro não residente na Republica.

(45) P. Bueno, obra citada, n. 85. 
á successão, não é licito negar-lhes o direito de promover a interdicção, pouco importando que esses parentes conservem a sua qualidade de extrangeiros (46).

XVII $\mathrm{O}$ direito de pedir alimentos, posto que fundado nas relações de parentesco, é um direito adquirido, dependente unicamente da condição de precisar o seu titular dos alimentos que a lei lhe assegura, conforme têm entendido a doutrina e a jurisprudencia (47). Consequentemente, a naturalisação de um individuo cuja nação de origem dá á obrigação de prestar alimentos maior extensão que o direito patrio, não produz o effeito de libertar o naturalisado da prestação devida pela lei da sua primitiva patria.

XXVIII No que toca aos direitos patrimoniaes em geral, não ha distincção entre os effeitos da naturalisação e os da promulgação de uma nova lei, isto é, sempre se applicam os principios e as regras da theoria da não retroactividade das leis, para o fim de se respeitarem os direitos adquiridos. E' verdade proclamada por todos os jurisconsultos.

XIX O direito de succeder em virtude de um testamento só é adquirido no momento da morte do testador; o direito de succeder em virtude da lei só é adquirido no momento da morte do de cujus (48). «La morte del de cujus è il punto di partenza per l'acquisto del diritto di succedere, cioè del divitto di accettare l'eredità per testamento o per legge» (49). Sendo assim, a consequencia logica é a que deduz Laurent, quando nos diz que inquestionavelmente a naturalisação de uma pessoa modifica o direito de successão a que estava sujeita essa pessoa, como

(46) Folleville, ns. 649 a $65 \mathrm{I}$.

(47) Folleville, ns. 654 a 663.

(48) GABBA, obra citada, vol. 3. ${ }^{\circ}$, pag. 243.

(49) Obra citada, vol. $3 .^{\circ}$, pag. 259. 
em geral os seus direitos civis, desde que não haja lesão de direitos adquiridos (50). Os parentes do naturalisado herdarão na ordem e de conformidade com o direito civil da nova patria (5 I).

XX O estudo dos effeitos civis da naturalisação 6 grandemente util; porquanto, entre as duas doutrinas - a do domicilio e a da nacionalidade-esta ultima é a que tende a prevalecer. Triumphante no dominio da sciencia (52), a doutrina da nacionalidade foi consagrada pelos dois melhores e mais adeantados codigos do seculo XIX, o Cod. Civil Italiano, (art. 6. ${ }^{\circ}$ da lei preliminar), que é o Cod. Napoleão retocado ou aperfeiçoado, e o Cod. Civil Allemão, (art. $70^{\circ}$ da lei de introducção).

Sobre a theoria do domicilio tem a da nacionalidade as duas grandes excellencias de: I. $^{\circ}$ imprimir ao estatuto pessoal uma certa estabilidade, visto como a mudança de nacionalidade não é tão facil, nem tão commum, nem dá tanto azo ás machinações da fraude, como a mudança do domicilio; $20^{\circ}$ facilitar, simplificar, nos limites do possivel, as complicadissimas questões do direito internacional privado.

No Brasil é a theoria da nacionalidade a que tem prevalecido (53).

XXI Importa notar, finalmente, que a naturalisação só é valida, e produz os effeitos civis assignalados,

(50) Obra citada, vol. $3 .$, n. 318

(5I) Morrendo um cidadão naturalisado, que não deixe herdeiros, a herança, de accordo com o direito patrio, é devolvida á Fazenda Publica.

Ainda na hypothese de ser o de cujus extrangeiro, a mesma regra de direito se applica, isto é, a Fazenda Publica é a herdeira dos extrangeiros que fallecem no Brazil, aqui deixando bens, como se vê no relatorio do ministerio do exterior de 1895 (Direito, vol. 68, pag. 328).

Vide tambem C. de Carvalho, Nova Consolidaşão das Leis Civis, arts. 31 e 32.

(52) LAURENT, vol. $30^{\circ}$, n. 280.

(53) P. Bueno, obra citada, passim. Carlos de Carvalho, Nova Consolidasão das Leis Civis, art. 25. 
quando não obtida fraudulentamente, ou para fins diversos da acquisição de uma nova patria.

Desse vicio é inquinada a naturalisação, quando o naturalisado só tem em vista, por exemplo, subtrairse ás consequencias legaes de um delicto perpetrado no paiz de origem, forrar-se aos incommodos do serviço militar, ou obter a decretação de um divorcio que as leis de sua nação anterior não permittiam. Tanto é verdadeiro o brocardo--fraus omnia corrumpit.

Dr. Bedro Sessa. 